\title{
A DIARY USING FUZZY SETS
}

\author{
Wilson Castello Branco Neto \\ castello@eps.ufsc.br \\ Universidade Federal de Santa Catarina (UFSC)
}

Fernando A. O. Gauthier gauthier@inf.ufsc.br

Universidade Federal de Santa Catarina (UFSC)

$B R A Z I L$

This paper presents a software similar to a diary, where all the members of a team or company are registered. When a meeting is needed, the teleworker has only to enter the possible dates e times for the meeting. The others members are notified by e-mail, then, each member can get into the system to say what his role is in the proposed schedule. The Fuzzy Sets Theory is used to make the data enter as natural as possible and to choose the best schedule so that the meeting can be booked. This software is being developed to run on a web server, allowing the registered people to have access to it from any computer connected to the Internet.

\section{INTRODUCTION}

Recent researches about telework indicated the interaction among its participants as one of the key points for the success of the companies that adopted this strategy. The benefits of time and space independence became a problem that must be dealt carefully, because working in different places and times make the interaction among staff very difficult.

This paper proposes the development of a diary to facilitate the meetings' booking between people who work in the same company, department or project, however in different places or times. The diary's objective is booking meetings automatically considering the appointments of the involved people.

The imprecision in concepts used in our every day life, showed that it is not enough only to allow users define whether they are busy or free in a moment, because the appointment's importance can vary, some of them, for example, can be postponed due to other appointments and some cannot. This problem leads us to use fuzzy sets.

This paper is organised as follows: First it is done a brief explanation about telework and its effects nowadays, next is presented fuzzy sets theory, its definition and its main operators. Another section explains how this diary works and its main 
features. In the last section it can be seen how fuzzy sets has been used in this problem.

\section{TELEWORK}

Telework occurs when information and communications technologies (ICTs) are applied to enable work to be done at a distance from the place where the work have been done. It is a practice that has been being used for more and more people all around the world, every day. Telework is made attractive by:

- Increasing pressure on industry to reduce costs while improving levels of customer service;

- Increasing concern about the environment and especially the impact of roads and cars;

- The emergence of a networked economy, in which telework and teletrade will play central roles;

As well as affecting the individual and the enterprise, telework has significant economic and trade implications, for example many jobs in computer programming that might previously have been done in California can now be done in the third world countries.

\section{FUZZY SETS}

Fuzzy sets theory was developed in 1965 by Zadeh to work with problems very complex to solve using conventional mathematical methods [1]. Complex problems are those ones that do not have a well-defined boundary and it is difficult to define whether an object is a member of a set or not.

Fuzzy sets theory uses membership function concept. This function accept values on the interval $[0,1]$, and represents the degree of membership of an object in a set. Aiming to better illustrate this concept, a membership function will be defined to the set "young".

$$
\mu_{\mathrm{A}}(\mathrm{x})=-\left\{\begin{array}{cc}
1 & (0 \leq \mathrm{x} \leq 20) \\
(70-\mathrm{x}) / 50 & (20 \leq \mathrm{x} \leq 70) \\
0 & (70 \leq \mathrm{x})
\end{array}\right.
$$

The set's graphic definition is shown in figure 1 .

Degree of

Membership

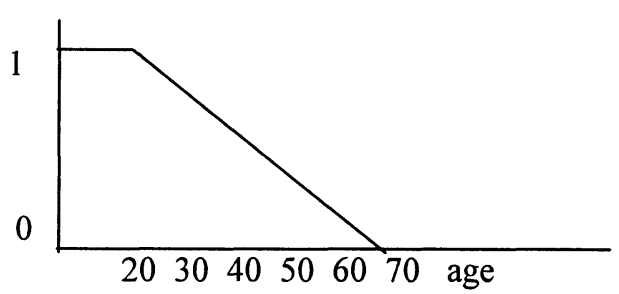

Figure 1 - Young Set's Degree of membership. 
As classical sets, fuzzy sets also have some operations that can be done on them. Next, some of these operations are described [2].

\section{Equality}

Two fuzzy sets are equal just if their membership functions are equal. Given two sets $A, B \in S$

$$
\mathrm{A}=\mathrm{B} \Leftrightarrow \mu_{\mathrm{A}}(\mathrm{x})=\mu_{\mathrm{B}}(\mathrm{x}), \forall \mathrm{x} \in \mathrm{S}
$$

\section{Union}

The union of two fuzzy sets is defined by the maximum operator between their membership functions.

$$
\mathrm{A} \cup \mathrm{B}: \mu_{\mathrm{A} \cup \mathrm{B}}(\mathrm{x})=\max \left[\mu_{\mathrm{A}}(\mathrm{x}), \mu_{\mathrm{B}}(\mathrm{x})\right] \text {. }
$$

\section{Intersection}

The union of two fuzzy sets is defined by the minimum operator between their membership functions.

$$
A \cap B: \mu_{A \cap B}(x)=\min \left[\mu_{A}(x), \mu_{B}(x)\right] .
$$

\section{Complement}

A fuzzy set's complement is given by:

$$
\mathrm{A}: \mu_{\mathrm{A}}(\mathrm{x})=1-\mu_{\mathrm{A}}(\mathrm{x}) \text {. }
$$

\section{Alpha Cut}

Given a fuzzy set $A$, it is defined as $A_{\alpha}$ the set where:

$\mathrm{A}_{\alpha}=\left\{\mathrm{x} \mid \mu_{\mathrm{A}}(\mathrm{x})>\alpha\right\}$

Fuzzy sets membership functions can have different shapes, but aiming to make easier the software implementation, generally it is used triangular and trapezoid functions. The last ones have been used in this work.

\section{MEETING DIARY}

The diary shown in this paper is a tool available for managers and employees who telework either part or mainly full time. Its objective is to facilitate meeting booking among people who work in the same company, department or project. It works as follows.

The system runs on Windows NT with any web server, and it can be accessed through the Internet. Every meeting is proposed by a manager who is registered in the system. When it is done, the manager is not asked about only one, but about some possible schedules for it, besides that, he must inform the duration, and how important the meeting is. Figure 2 shows the interface used for meeting's data entry.

After these data have been entered, the system automatically warns the employees, by e-mail, about this request. Then, using their diary tool, shown in figure 3 , they say how busy they are in the date and time proposed. In this interface, 
it is indicated the possible date and time intervals for the meeting. This interval is divided into subintervals of 30 minutes each, and employees are supposed to define their occupation degree in each subinterval.

After all employees have defined their occupation in that time interval, the system looks for the best time to book the meeting considering employees' schedule. Next, a ranking with the best times is shown to the manager, so that he can choose one of them and let the interested people know about the meeting time.

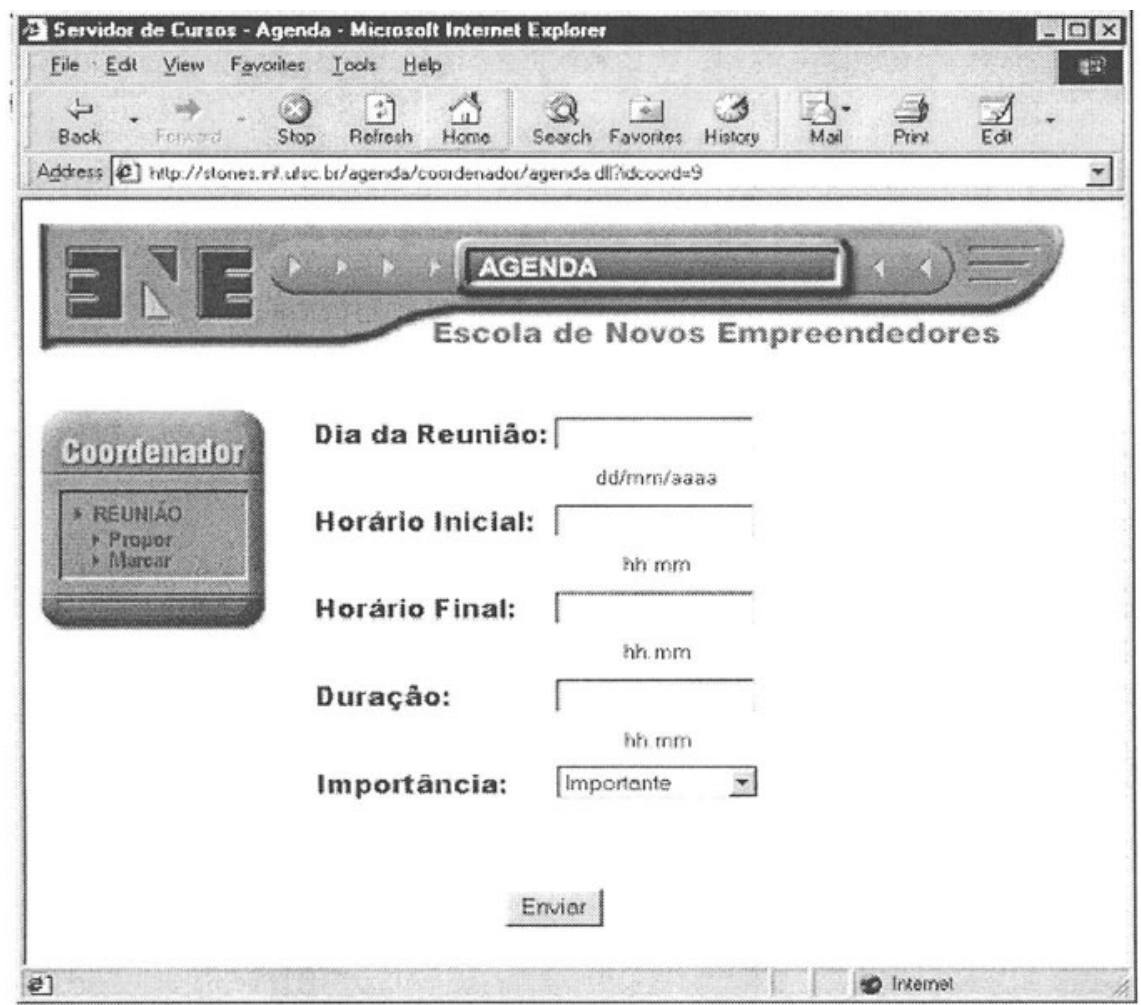

Figure 2 - Interface for meeting's data entry.

The process of defining employees' occupation, and best schedule chosen was implemented using fuzzy sets theory. Its aspects and a system detailed description are in the next section.

\section{FUZZY SETS APPLICATION}

This work uses fuzzy sets theory in the following way: first, five fuzzy sets that determine the employee occupation in a specific time and date were defined. These sets are shown below and their graphic representation can be seen in figure 4 .

1. Pressing appointment;

2. Very important appointment;

3. Important Appointment; 
4. Not so important appointment;

5. Free.

Due to the difference between peoples' concepts interpretation, the system allows that each user owns a set like this one shown in figure 4, and configure the variables $\mathrm{a}-\mathrm{h}$ so they can represent the concepts in their way.

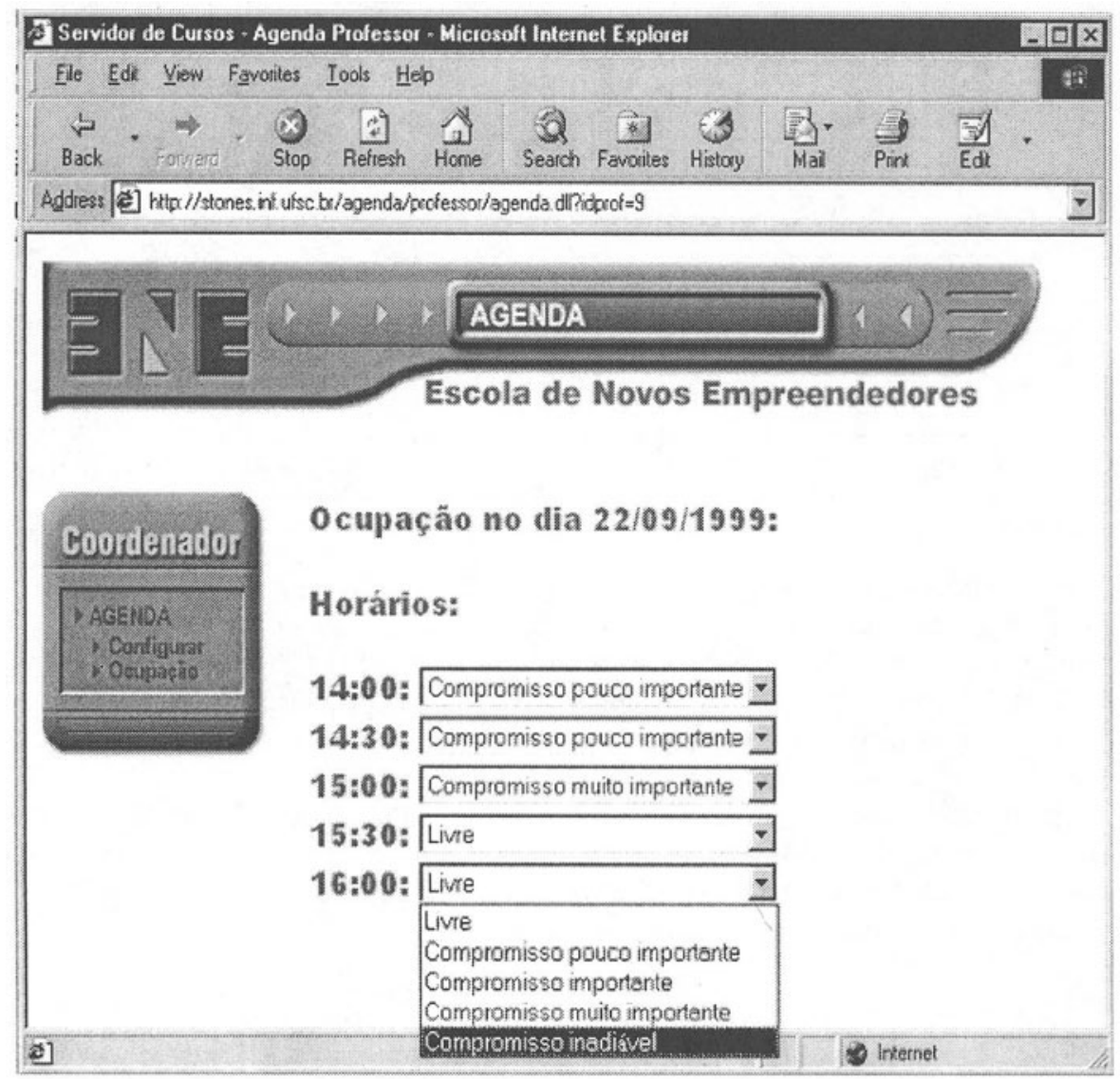

Figure 3 - Interface to define each employee occupation.

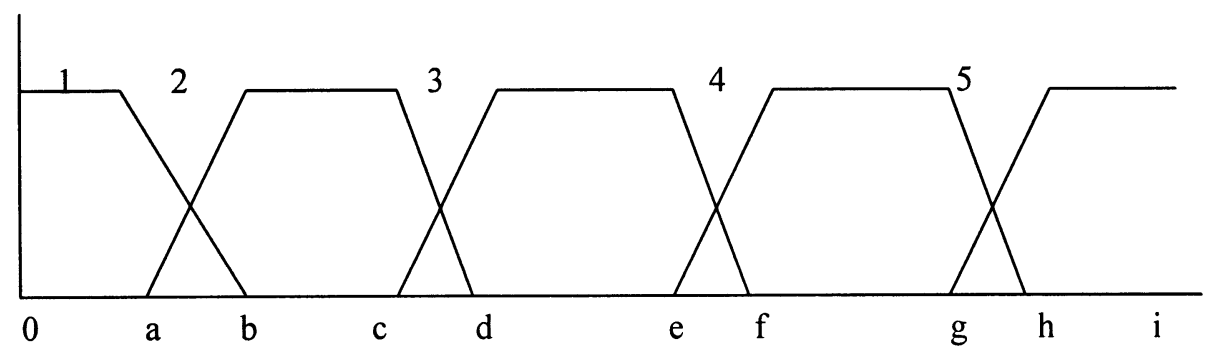

Figure 4 - User configuration set 
This way, each set will have the fuzzy values shown in table 1.

When a meeting is proposed by a manager, a new set is created and its support is the interval of possible times for the meeting. Through the interface shown in figure 3 , each employee defines his occupation in each subinterval of 30 minutes. When a option is chosen to define this occupation, one of the fuzzy sets shown in the table above is selected with the values previously configured.

Table 1 - Fuzzy Values

\begin{tabular}{|c|c|}
\hline Fuzzy Set & Fuzzy Value \\
\hline Pressing appointment & $(0,0, \mathrm{a}, \mathrm{b})$ \\
\hline Very important appointment & $(\mathrm{a}, \mathrm{b}, \mathrm{c}, \mathrm{d})$ \\
\hline Important Appointment & $(\mathrm{c}, \mathrm{d}, \mathrm{e}, \mathrm{f})$ \\
\hline Not so important appointment & $(\mathrm{e}, \mathrm{f}, \mathrm{g}, \mathrm{h})$ \\
\hline Free & $(\mathrm{g}, \mathrm{h}, \mathrm{i}, \mathrm{i})$ \\
\hline
\end{tabular}

Next all users have defined their occupation, the system make an intersection of the sets chosen for each subinterval. The resulting set of this intersection is defuzzyficated by using mean-max membership method[2]. This method has some features that were considered in its choose, the most important is that it can be used in sets whose membership functions is a plateau, and for being easy for implementing.

After defuzzyfication, it is built a new fuzzy set called "Employees' Occupation", shown in figure 6 , whose support is the time interval proposed by manager for the meeting, divided in subintervals of 30 minutes, and the membership values are the results of defuzzyfication, previously mentioned.

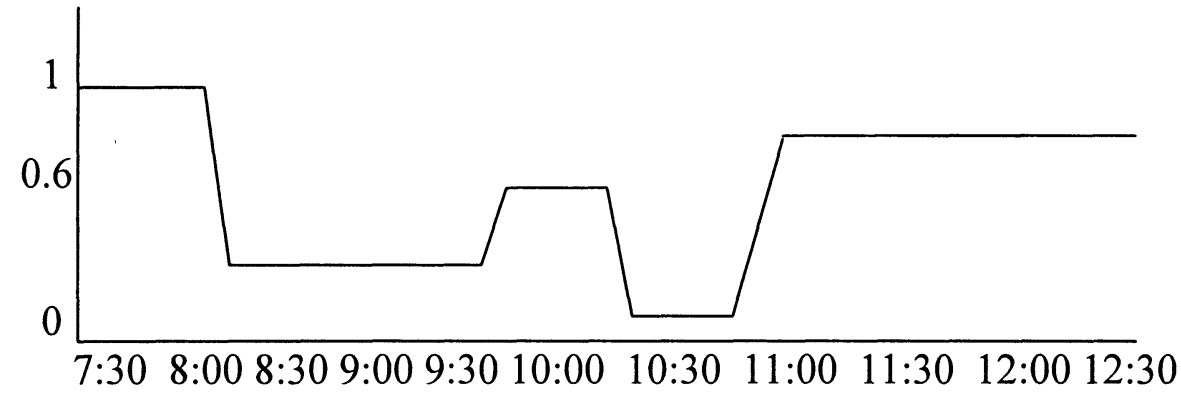

Figure 6 - Employees' Occupation Set 
An alpha cut is done in this set, considering the importance of the meeting. The intervals in the resulting set are possible schedules for the meeting. In figure 7, it is shown the fuzzy set resulting after an alpha cut has been done in the set in figure 6 .

This graphic shows that the meeting can be booked, at 7:30, if its duration is less then 30 minutes, or any time between 11:00 and 13:00. All this possible schedules are shown to the manager as a ranking so that he can choose the best one.

When no possible schedule has been found to book the meeting, the system automatically, take the busiest employee in each time interval out, and do all the process (intersection, building and cut) again. This strategy of taking out only one person each time, aims to allow as most as possible people can participate of the meeting and it is repeated until the meeting can be booked.

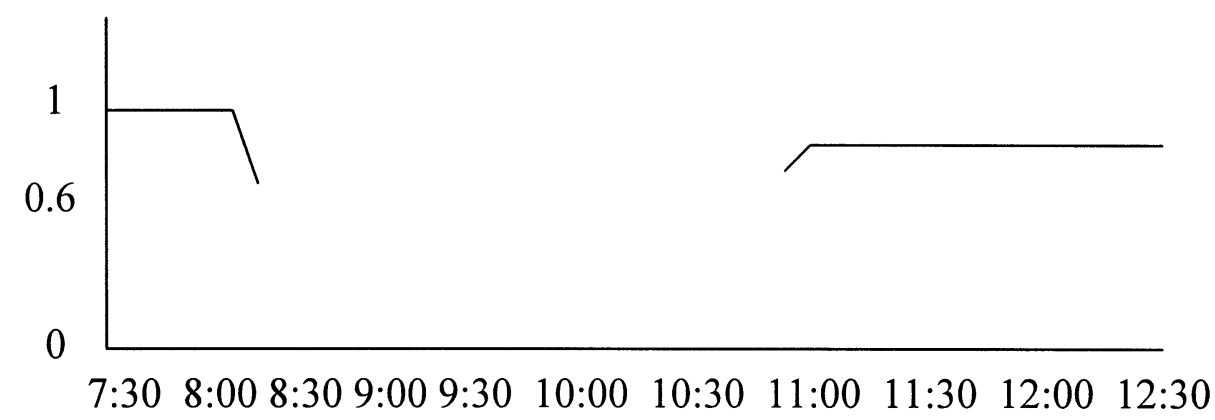

Figure 7 - Possible Schedules for the meeting.

\section{CONCLUSION}

This paper presented a tool whose objective is to minimize the problem of missing interaction between staff and managers involved in telework. This tool, uses fuzzy sets to book meetings aiming improve the communication among these people.

Considering that this work is still being developed, the present results are satisfactory. This system has not been used for many people at the same time in a real environment, but the tests made showed that its performance come up to expectations. As well as fuzzy sets had a good performance in the interaction between system and users, making the data entry as natural and simple as possible.

The program developed is not specific for teleworkers. Big companies, for example, could use it to book meetings among managers or employees from different departments, and in many other situations where booking a meeting is almost impossible. 


\section{REFERENCES}

1- KLIR, J. George, FOLGER, A. Tina. Fuzzy Sets, Uncertainty and Information. Prentice - Hall, New Jersey, 1988.

2- ROSS, J. Timothy. Fuzzy Logic with Engineering Applications. McGraw-Hill, New York, 1995. 